\title{
EFFECTIVENESS OF THREE ROTARY NITI INSTRUMENTS AND HAND INSTRUMENTATION IN REMOVING GUTTA PERCHA FROM ROOT CANALS: AN IN VITRO STUDY
}

Neelkamal $^{1}$, Varun Jindal ${ }^{2}$, Ajay Chhabra ${ }^{3}$, Damanpreet ${ }^{4}$

${ }^{1}$ PG Student, Department of Conservative Dentistry \& Endodontics, Bhojia Dental College \& Hospital, Himachal Pradesh, India

${ }^{2}$ Reader,Department of Conservative Dentistry \& Endodontics, Bhojia Dental College \& Hospital, Himachal Pradesh, India

${ }^{3}$ Professor \& Head, Department of Conservative Dentistry \& Endodontics, Bhojia Dental College \& Hospital, Himachal Pradesh, India

${ }^{4}$ Reader,Department of Conservative Dentistry \& Endodontics, Bhojia Dental College \& Hospital, Himachal Pradesh, India

\begin{abstract}
Objectives: The study aimed to assess variation in the remaining filling material by radiographic analysis and the time taken for retreatment system, with H-files; the ProTaper Universal Retreatment System; Mtwo Retreatment system and the SybronEndo K3. Methods: 120 human mandibular premolars with single straight root canals were prepared with rotary twisted files (up to size 40/0.04) using the crown down technique and filled by cold lateral compaction and the radiographs were taken. After one week, teeth were divided into four groups $(\mathrm{n}=30)$. Gutta-Percha was removed using H-files, the ProTaper Universal Retreatment System, Mtwo system and the K3 System. After retreatment radiographs were taken for each sample and the remaining material was calculated for each canal third. Results: Rotary NiTi instruments were significantly faster than the hand instrumentation technique in performing the retreatment. In radiographic analysis there was significant difference in between the groups for coronal third in ProTaper group and for apical third in H-file group. Conclusions: In the radiographic analysis the ProTaper Universal Retreatment System left less filling material in the coronal third and the H-files left less filling material in apical third as compared to other groups. Rotary instruments worked faster than $\mathrm{H}$ files.
\end{abstract}

Key Words: Retreatment, Radiograph, ProTaper Universal Retreatment System, Mtwo system, K3 System, Hedstrom files, Filling material, Gutta Percha.

\section{INTRODUCTION}

The main objective of endodontic treatment is to clean, shape and obturate all the portals of root canal system, threedimensionally to prevent reinfections ${ }^{1}$. Root canal therapy despite having a high degree of success, may not lead to desired response and failure may occur. ${ }^{2}$ Although success rates are varying between $86 \%$ and $98 \%$, endodontic therapy may result in failures by a number of biological and technical factors such as untreated canals, ${ }^{4}$ perforations, ${ }^{5}$ inadequately filled canals, ${ }^{6}$ coronal leakage. ${ }^{7}$ These factors cause persistency of bacteria within the root canal system and as a result the microorganisms or their byproducts may induce an inflammatory response within the peri-apical tissue causing periradicular lesions. When peri-apical disease is formed, the options for treatment are non-surgical re-treatment, surgical procedures or surgical extraction of the tooth. ${ }^{3}$ Among those non-surgical root canal re-treatment, which is an attempt to re-establish peri-apical tissues after inadequate treatment or reinfection of an obturated root canal system has become a routine practice in dentistry because of the etiological factors. ${ }^{8}$

The main goal of orthograde retreatment is regaining access to the apical foramen by complete removal of root canal filling material, thus facilitating sufficient cleaning and shaping of complete root canal system and final obturation. ${ }^{8}$ Only if the filling material can be removed completely and root canal negotiated to the apical foramen, allowing thorough debridement, can the prerequisites for a successful re-treatment be fulfilled. ${ }^{9}$ 
Although numerous materials have been described for obturation of root canals, Gutta-Percha in combination with a sealer is the most frequently used material. ${ }^{9,10}$

Removal of obturation material can be effected with hand files, heat carriers or ultrasonic instruments or engine driven rotary files with or without the aid of solvent. In many cases the combined use of different techniques may be the most efficient and time saving method. ${ }^{9,11}$

Conventionally, H Files with or without solvent have been used in routine practice for the removal of filling materials from the root canals. Rotary Ni-Ti instruments have also been proposed for the same. Review of literature revealed that only few studies ${ }^{12,13}$ investigated the effectiveness of rotary files in the removal of Gutta-Percha during endodontic retreatment.

Hence, the aim of this in-vitro study is to compare the efficiency of $\mathrm{H}$ files, ProTaper Universal Retreatment files, Mtwo re-treatment files and SybronEndo K3 retreatment system; during root canal re-treatment for the removal of Gutta Percha in straight canals.

\section{MATERIALSAND METHOD}

One hundred twenty single, straight rooted freshly extracted mandibular premolar teeth, each with one single root canal, were used. Following extraction, soft tissue and calculus were mechanically removed from the root surfaces. The teeth were stored for two days at room temperature in $3 \% \mathrm{NaOCl}$ to remove organic debris. Subsequently they were stored in normal saline solution which was changed every two weeks until the procedure was initiated.

The length of specimens was standardized. All samples were marked at $16 \mathrm{~mm}$ from the apex with the help of verneer caliper. The specimens were then sectioned at this mark using diamond disc. A size $10 \mathrm{~K}$ file was inserted into the canal until it was visible at the apical foramen and the working length was determined to be $1 \mathrm{~mm}$ short of this position. Apical patencies were determined with a size $10 \mathrm{~K}$-file. A glide path was then made upto size of $20 \mathrm{~K}$-file till working length.

\section{Root canal preparation and obturation}

All the canals were instrumented with NiTi twisted rotary files with size 25 and 35 of 0.08 and 0.06 taper respectively in a crown down manner using a 16:1 reduction handpiece powered by a torque controlled electric motor operated at $500 \mathrm{rpm}$. Final apical preparation was done with 40/0.04 NiTi twisted file.

The canals were irrigated copiously using $2 \mathrm{ml}$ of $3 \%$ sodium hypochlorite solution after each instrument was used and before proceeding to the next one. The solution was carried to the canal using 30 gauge MAXI-Probe. It was inserted passively upto $1 \mathrm{~mm}$ short from the working length. When instrumentation was complete, $17 \%$ EDTA was applied for three minute to remove the smear layer followed by a final rinse with 3 $\mathrm{ml}$ of normal saline to remove the previously used solutions to allow better contact of the sealer with the root canals walls. The root canals were then dried with absorbent paper points.

For obturation a master Gutta-Percha cone ISO size 40 was selected and tug-back was checked. The root canals were filled with cold lateral condensation of Gutta-Percha and AH plus sealer. Thereafter, accessory Gutta-Percha cones ISO sizes 20 and 25 were laterally compacted using finger spreaders. A heated plugger was used to remove the coronal $1 \mathrm{~mm}$ of Gutta-Percha. This $1 \mathrm{~mm}$ of space was filled by temporary restoration (Cavit Temp).

Subsequently, the quality and apical extent of the root canal filling was accessed with digital radiograph in buccolingual direction using a radiographic grid. The distance between the X-ray source and radiographic film and the direction of the beam were same throughout the study. The exposure time was $0.4 \mathrm{~s}$ and the films were automatically processed. All teeth were stored in 100\% humidity at 37 degrees celsius for 1 week to allow complete setting of sealer. After 1 week temporary restorations were removed and the root canals were reopened.

\section{Reinstrumentation technique}

After removal of the temporary restoration the teeth were then randomly divided for retreatment into four groups of 30 specimens each $(n=30)$. 
Group 1 (ProTaper): This group received the retreatment by ProTaper Universal Retreatment files used in the crown down motion using a brushing action with lateral pressing movements according to the manufacturer's instructions. Instruments were used in following manner: D1 (30/0.09) was used for the cervical third; D2 (25/0.08) for the middle third; D3 (20/0.07) for the apical third until the working length was used. Instrumentation was completed when the D3 instrument reached working length, and no additional root canal filling material could be recovered on the instrument.

Group 2 (K3): K3XF instruments were used in a crown-down manner according to manufacturer's instructions using gentle in-and-out motion. Instruments were withdrawn when resistance was felt and changed for the smaller number instrument. File sequences were as follows: size 25/0.06 was used at one half of the working length; size 20/0.06 was used between one half and two-thirds of working length; and instruments of sizes 20/0.04, 25/0.04 and 30/0.04 were used to the working length.

Group 3 (Mtwo): For the retreatment in this group Mtwo retreatment file 15/0.05 was advanced in the root canal in a brushing action with lateral pressing movements. Then the final apical cleaning was done by $25 / 0.05$ instrument at a speed of $300 \mathrm{rpm}$ and a torque of $1.2 \mathrm{Ncm}^{-1}$. All the instruments were used to the full length of the canals using a gentle in and out motion.

Group 4 (H files): The canals were reinstrumented with $\mathrm{H}$ files in ISO sizes 70, 60, 55, 50 and 40 of 0.02 taper in a circumferential quarter-turn push-pull filing motion to remove Gutta Percha and sealer from the canal. The instruments were used in a crown down motion until an end-point at which working length was reached with a size 40 Hedstrom file, and no additional root canal filling material could be recovered on the file.

During retreatment, root canals were constantly irrigated with $3 \% \mathrm{NaOCl}$ and $17 \%$ EDTA. The radiographs were taken after removal of filling material as described previously.

\section{EVALUATION METHODS}

Time for Retreatment: The time required to achieve satisfactory Gutta Percha removal was recorded for each technique and were tabulated. The time elapsed from entering the root canal with hand files or rotary files including irrigation and completion of the reintrumentation was measured in seconds with a stop watch. Time taken to change the instruments was not included in the retreatment time.

Radiographic Evaluation: The roots were then radiographed again in buccolingual direction using a radiographic grid (Figure 1). In the radiograph each third of the canals were evaluated for the remaining root fillings by counting the grids. The area of radio-opaque material in each thirds of the canal were measured and expressed as a percentage of the root canal area.

\section{RESULTS}

The statistical software SPSS PC+ Version 4.0.1 was used for statistical analysis.

\section{Time analysis:}

Mean and standard deviation was estimated for the time taken by the different instruments for the removal of filling materials from the root canal (Table 1.1) and the values were compared with two way anova test for the estimation of level of significance (Table 1.2) (Graph 1). $\mathrm{p}<0.05$ was considered as the level of significance.

Test of significance between the means show that there was a significant difference between the groups for the time taken by the different instruments for retreatment. Group 4 took the maximum time duration

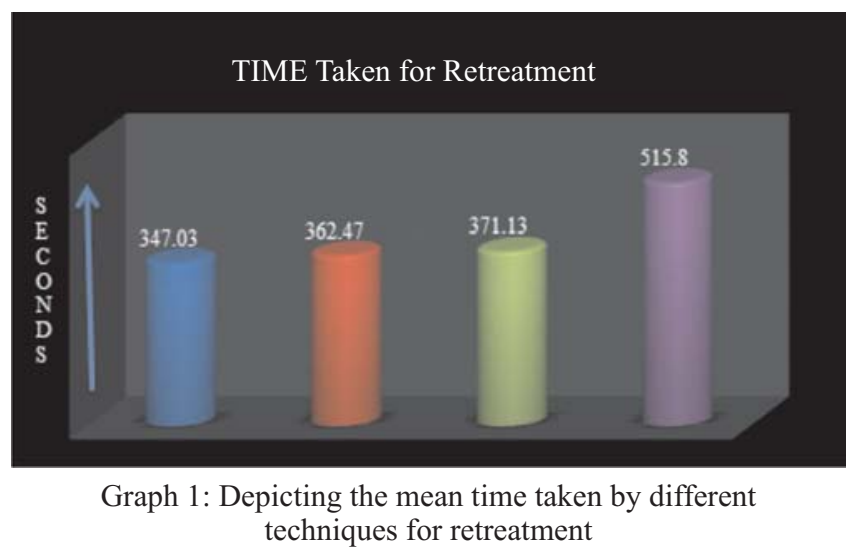


Table 1.1: Time taken by different groups for retreatment in seconds

\begin{tabular}{|c|l|l|}
\hline Group & \multicolumn{1}{|c|}{ Mean \pm STD deviation } & P value \\
\hline 1. & $347.03 \pm 29.712 \mathrm{sec}$. & 1.463 \\
\hline 2. & $362.47 \pm 27.04 \mathrm{sec}$. & 1.65 \\
\hline 3. & $371.13 \pm 25.869 \mathrm{sec}$. & 0.578 \\
\hline 4. & $515.8 \pm 22.789 \mathrm{sec}$. & 0.432 \\
\hline
\end{tabular}

Table 1.2: ANOVA Test for time analysis

\begin{tabular}{|c|c|c|}
\hline Pair & p-value & Significance \\
\hline Grp 1 vs Grp 2 & 1.03 & Ns \\
\hline Grp 1 vs Grp 3 & 0.67 & Ns \\
\hline Grp 1 vs Grp 4 & 0.033 & ${ }^{*} \mathrm{p}<0.05$ \\
\hline Grp 2 vs Grp 3 & 1.05 & Ns \\
\hline Grp 2 vs Grp 4 & 0.037 & ${ }^{*} \mathrm{p}<0.05$ \\
\hline Grp 3 vs Grp 4 & 0.031 & ${ }^{*} \mathrm{p}<0.05$ \\
\hline
\end{tabular}

(mean $=515.8 \mathrm{sec}$.) when compared to the other groups (mean ranging from 347-371 sec.) and this difference of duration was significant when compared to other groups $(\mathrm{p}<0.05)$.

\section{Radiographic analysis}

Mean and standard deviation was estimated for each group for percentage of residual filling material as calculated by the radiographic analysis for each canal third (Table 2.1).

Tukeys test was done for intergroup comparison to calculate the level of significance (Table 2.2) (Graph 2). Coronal: Group one had less percentage of remaining debris when compared to all the other groups and the difference was significant when group 1 was compared to group $3(\mathrm{p}=0.032)$. Middle: Test of significance between the groups showed no significant difference for the canal wall cleanliness in middle third as calculated by radiographic analysis. Apical: In the apical region Group 4 had the fewer percentages of remaining debris among all the other groups. There was a significant difference between the groups for the canal wall cleanliness in apical third for Group 4 when compared to Group 1 ( $\mathrm{p}=0.026)$ and Group 3 (0.048).

\section{DISCUSSION}

One of the parameters that was most difficult to control was the extent of the anatomical variations that are generally present in human teeth. Variations in original root canal morphology greatly influence the changes that occur after root canal preparation and as a

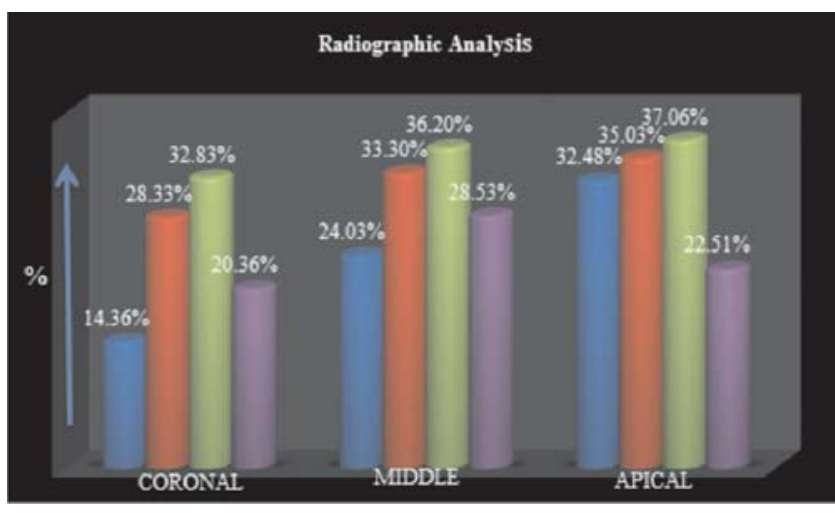

Graph 2: Depicting the mean percentage of remaining debris in different groups as calculated by radiographic analysis

Table 2.1: Radiographic analysis for percentage of remaining debris

\begin{tabular}{|c|l|l|l|c|}
\hline Group & Area & Mean \pm Std deviation & p value & Significance \\
\hline \multirow{3}{*}{1} & Coronal & $14.36 \pm 32.42$ & 0.0789 & Ns \\
\cline { 2 - 5 } & Middle & $24.03 \pm 13.005$ & 0.089 & Ns \\
\cline { 2 - 5 } & Apical & $32.48 \pm 12.012$ & 0.0987 & Ns \\
\hline \multirow{2}{*}{2} & Coronal & $28.33 \pm 53.238$ & 0.0654 & Ns \\
\cline { 2 - 5 } & Middle & $33.3 \pm 24.65$ & 0.076 & Ns \\
\cline { 2 - 5 } & Apical & $35.03 \pm 11.0256$ & 1.765 & Ns \\
\hline \multirow{3}{*}{3} & Coronal & $32.83 \pm 33.173$ & 1.098 & Ns \\
\cline { 2 - 5 } & Middle & $36.2 \pm 36.34$ & 0.976 & Ns \\
\cline { 2 - 5 } & Apical & $37.066 \pm 10.816$ & 2.986 & Ns \\
\hline \multirow{3}{*}{4} & Coronal & $20.36 \pm 56.198$ & 1.987 & Ns \\
\cline { 2 - 5 } & Middle & $28.53 \pm 22.59$ & 1.114 & Ns \\
\cline { 2 - 5 } & Apical & $22.51 \pm 9.374$ & 1.654 & Ns \\
\hline
\end{tabular}

Table 2.2: Tukey test for radiographic analysis

\begin{tabular}{|l|l|l|l|}
\hline Coronal & Pair & p-value & Interference \\
\cline { 2 - 4 } & & & \\
\cline { 2 - 4 } & Grp 1 vs Grp 2 & 0.037 & Ns \\
\cline { 2 - 4 } & Grp 1 vs Grp 3 & 0.032 & * $<0.05$ \\
\cline { 2 - 4 } & Grp 1 vs Grp 4 & 0.072 & Ns \\
\cline { 2 - 4 } & Grp 2 vs Grp 3 & 0.31 & Ns \\
\hline \multirow{4}{*}{ Middle } & Grp 2 vs Grp 4 & 0.35 & Ns \\
\cline { 2 - 4 } & Grp 3 vs Grp 4 & 0.083 & Ns \\
\hline & Grp 1 vs Grp 2 & 0.89 & Ns \\
\cline { 2 - 4 } & Grp 1 vs Grp 3 & 0.08 & Ns \\
\cline { 2 - 4 } & Grp 1 vs Grp 4 & 0.47 & Ns \\
\cline { 2 - 4 } & Grp 2 vs Grp 3 & 0.093 & Ns \\
\cline { 2 - 4 } & Grp 2 vs Grp 4 & 0.25 & Ns \\
\cline { 2 - 4 } & Grp 3 vs Grp 4 & 0.77 & Ns \\
\hline \multirow{5}{*}{ Apical } & Grp 1 vs Grp 2 & 0.66 & Ns \\
\cline { 2 - 4 } & Grp 1 vs Grp 3 & 1.05 & Ns \\
\cline { 2 - 4 } & Grp 1 vs Grp 4 & 0.026 & * p $<0.05$ \\
\cline { 2 - 4 } & Grp 2 vs Grp 3 & 0.099 & Ns \\
\cline { 2 - 4 } & Grp 2 vs Grp 4 & 0.065 & Ns \\
\cline { 2 - 4 } & Grp 3 vs Grp 4 & 0.048 & * $<<0.05$ \\
\hline
\end{tabular}



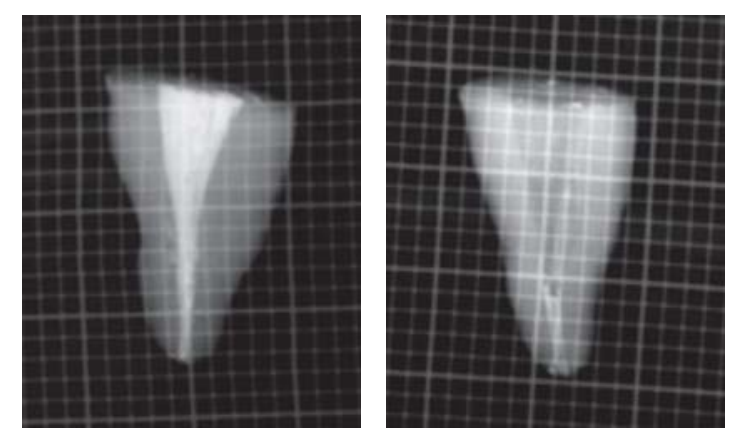

Figure 1: Pre and post retreatment radiographs for group 1

logical extension, after retreatment procedures. ${ }^{14}$ In order to minimize these variables a standardized length of root canal filling was adhered to and only teeth with straight canals were selected.

From the results it was observed that group that was retreated using $\mathrm{H}$ files (Group 4) took the maximum time to remove the filling material. Shortest time was recorded in ProTaper Universal Retreatment file group (Group1). The results are also consistent with a study by J. J. Ferreira et $\mathrm{al}^{10}$ who compared the efficacy of ProFiles, K-Flexo files and $\mathrm{H}$ files and found that rotary files worked faster than hand files for retreatment of root canal. Another study by O. Zmener et $\mathrm{al}^{15}$ compared the retreatment efficacy of hand versus automated instrumentation in oval-shaped root canals. They also found that the retreatment time for rotary files was significantly shorter compared to manual instrumentation with Hedstrom files.

A possible explanation for this could be that rotary instruments were used in the rotational motion, whereas $\mathrm{H}$-file was used in push pull filling action. It is believed that the rotary motion of NiTi files plasticize the Gutta Percha resulting in easy penetration of instrument which further makes it easier to remove from the canals. ${ }^{10}$

Furthermore, the high performance of ProTaper Universal Retreatment files can be explained because of its flute design. According to Hulsmann and Bluhm, ${ }^{9}$ ProTaper retreatment files frequently removed large amount of Gutta-Percha in spirals around the instruments, whereas H-files mainly removed Gutta Percha in small increments that did not adhere to the instruments. This explains the time taken for retreatment by H-files.
Generally it has been observed from the previous studies ${ }^{16-18}$ that the Gutta-Percha removal varies in the different thirds of a canal with different instruments. Hence, in the present study we have separately analyzed the amount of filling material left in the canal for the different experimental instruments for all the thirds.

Radiographic analysis revealed that it was impossible to remove the filling materials completely from the root canals with any retreatment techniques. All the techniques left some amount of filling material in the canals.

The results showed a significant difference for the group 4 ( $p=0.048$ when compared to group 3 and $p=0.926$ when compared to group 1) in the apical region in comparison to the other groups. H files showed better cleaning in the apical region. For the coronal third there was a significant difference seen among the groups with group $1(\mathrm{p}=0.032$ when compared to group 3) showing significantly lesser filling debris in comparison to other three groups. However no significant difference was observed among the groups in middle third with all the groups showing similar performance rates.

Regardless of the technique, more residual canal filling material remained in the apical third, which is consistent with the previous studies. ${ }^{16,19}$ This has been attributed to increased anatomical variability as well as the difficulty of instrumentation in this region. ${ }^{20}$ Another possible explanation for this is that present study aimed to access the efficiency of the retreatment techniques in removing the filling material up to the working length; the last instrument used probably did not engage with the root canal walls in the apical portion. This explains the high performance of $\mathrm{H}$-files in this region as compared to other groups. The $\mathrm{H}$ file used for retreatment in the apical region was a \#40 file which corresponded to the apical preparation that was done with \#40 twisted file. However the taper of $\mathrm{H}$-file did not correspond as the apical preparation was done with a 0.04 taper which explains the reason of remaining material.

All the other groups showed a poor performance in the apical region with mean remaining 
debris ranging from $35-37 \%$. Again the possible explanation for this can be the non corresponding size and taper of the files used in this region. D3 instrument of ProTaper system has a diameter of 0.02 with $7 \%$ taper. In case of $\mathrm{K} 3$ system instruments of sizes $0.04 / 20,0.04 / 25$ and $0.04 / 30$ were used to the working length, and in case of $\mathrm{M} 2$ retreatment system the final apical area was cleaned by 25/0.05 instrument. None of these instruments sizes or tapers corresponds to the previously prepared size of apical area. Another explanation for the better performance of hand files can be due to its mode of use. H-Files used in present study were made to slight push pull motion along with circumferential filling, as compared to rotary instruments which only followed a rotary action. There is a possibility that circumferential filling technique tend to scrape off the filling material present on the walls.

For the middle and coronal thirds ProTaper Universal Retreatment system (Group 1) showed better performance $(\mathrm{p}=0.032, \mathrm{p}=0.08$ respectively) when compared to the other groups as observed in previous studies in literature..$^{21-23}$ The better performance of ProTaper Universal Retreatment files may be attributed to their flute design and progressive taper. The negative rake angles and the absence of radial land might permit a cutting action rather than planning action as compared to K3 and Mtwo retreatment system which have a noncutting tip and positive rake angle.

The second possible explanation can be progressive taper of D1, D2 and D3. The taper $(0.07$, 0.08 and 0.09 ) of these three instruments is greatest among all the other files used for retreatment (K3 with 0.04, M2 with 0.05 taper and $\mathrm{H}$ files with 0.04). ProTaper Universal Retreatment files have the maximum diameter in the middle and coronal thirds. These features may enable the retreatment instruments to cut not only the filling material but also the superficial layer of dentine during root canal filling removal. Moreover the specific flute design and rotary motion of ProTaper Universal Retreatment instruments tend to pull the Gutta Percha into the file flutes and direct it towards the orifice.

In the present study the retreatment was performed without chemical softener which is commonly used in clinical retreatment cases, also the taper of the files used for retreatment corresponded neither to the prepared size of the root canal nor to each other. In clinical situations these factors may complicate the effectiveness of the different file systems used for retreatment.

The measurement system used in this study has limitations. Even though computerized radiographs does not truly represent the canal surface as they are not a true measurement of either surface. The area covered by remnants of root canal filling in this type of image is only a projection of this parameter in a given direction. Nevertheless, there is no other practical method available. All these factors need to be considered in evaluating the file systems in retreatment of root canal.

\section{CONCLUSION}

Under the present experimental conditions all techniques were suitable for the removal of GuttaPercha/sealer in oval-shaped root canals. However, completely clean root canal walls could not be achieved with any of the three techniques that were tested. The mean percentage of remaining Gutta-Percha/sealer was significantly lesser for the PTUR group in the coronal and for $\mathrm{H}$ file group in middle thirds of the canal $(\mathrm{P}<0.001)$.

Rotary instruments are more time efficient when compared to Hand instrumentation technique.

\section{REFERENCES}

1. Trop M. The vital tooth-its importance in the study and practice of endodontics. Endod Topics 2003;5(1): 1

2. Saad A Y, Al-Hadlaq SM, Al-Katheeri NH. Efficacy of two rotary NiTi instruments in the removal of gutta-percha during root canal re-treatment. J Endod 2007;33:38-41

3. Roda SR, Gettlemen BH. Nonsurgical retreatment, In pathways of the pulp. $10^{\text {th }}$ ed. Cohan S, Hargreaves KM, eds. Mosby Elsevier, St. Louis: Missouri 2011;890-952

4. Wolocott J, Ishley D, Kennedy W, Johnson S, Minnich S, Meyers J. A 5 year clinical investigation of second mesiobuccal canals in endodontically treated and retreated maxillary molars. J Endod 2005;31:262-264

5. Orstavik D, Pitt-Ford TR. Prevention and treatment of apical periodontitis. In: Essential Endodontology. Wiley-Blackwell, New York 2008 
6. Chugal NM, Clive JM, Spångberg LS. Endodontic infection: some biologic and treatment factors associated with outcome. Oral Sur Oral Med Oral Path Oral Radiol Endod 2003;96:8190

7. Saunders WP, Saunders EM. Coronal leakage as a cause of failure in root-canal therapy: a review. Endod Dental Traumat 1994;10:105-108

8. Stabholz A, Friedman S. Endodontic retreatment: case selection and technique. Part 2: Treatment planning for retreatment. J Endod 1988;14:607-614

9. Hülsmann M, Bluhm V. Efficacy, cleaning ability and safety of different rotary NiTi instruments in root canal retreatment. Int Endod J 2004;37:468-476

10. J. J. Ferreira, J. S. Rhodes \& T. R. Pitt Ford. The efficacy of gutta-percha removal using ProFiles. Int Endod J 2001;34:267-274

11. Wilcox LR, Endodontic retreatment: ultrasonics and chloroform as the final step in reinstrumentation. J Endod $1989 ; 15: 125-128$

12. B. Marques da Silva, F. Baratto-Filho, D. P. Leonardi, A. Henrique Borges, L. Volpato \& F. Branco Barletta. Effectiveness of ProTaper, D-RaCe, and Mtwo retreatment files with and without supplementary instruments in the removal of root canal filling material. Int Endod $\mathrm{J}$ 2012;45:927-932

13. A. Kfir, I. Tsesis, E. Yakirevich, S. Matalon \& I. Abramovitz. The efficacy of five techniques for removing root filling material: microscopic versus radiographic evaluation. Int Endod J 2012;45:35-41

14. Peters OA, Laib A, Gohring TN, Barbakow F. Changes in root canal geometry after preparation assessed by high resolution computed tomography. J Endod 2001;27:1-6

15. O. Zmener, C. H. Pameijer \& G. Banegas. Retreatment efficacy of hand versus automated instrumentation in oval- shaped root canals: an ex vivo study. Int Endod J 2006;39:521-526

16. J. J. Ferreira, J. S. Rhodes \& T. R. Pitt Ford. The efficacy of gutta-percha removal using ProFiles. Int Endod J 2001;34:267-274

17. A. V. Masiero \& F. B. Barletta. Effectiveness of different techniques for removing gutta-percha during retreatment. Int Endod J 2005;38:2-7

18. E. Kosti, T. Lambrianidis, N. Economides \& C. Neofitou. Ex vivo study of the efficacy of $\mathrm{H}$-files and rotary $\mathrm{Ni}-\mathrm{Ti}$ instruments to remove gutta-percha and four types of sealer. Int Endod J 2006;39:48-54

19. R. Gergi \& C. Sabbagh. Effectiveness of two nickel-titanium rotary instruments and a hand file for removing gutta percha in severely curved root canals during retreatment: an ex vivo study. Int Endod J 2007;40:532-537

20. Daniel Pinto de Oliveira, Joao Vicente Baroni Barbizam, Martin Trope, and Fabricio B. Teixeira. Comparison Between Gutta-Percha and Resilon Removal Using Two Different Techniques in Endodontic Retreatment. J Endod 2006;32:362364

21. Schirrmeister JF, Wrbas K, Schneider F, Altenburger M, Hellwig E. Effectiveness of a hand file and three nickeltitanium rotary instruments for removing gutta-percha in curved root canals during retreatment. Oral Sur Oral Med Oral Patho Oral Radiol Endod 2006;101:542-7

22. de Carvalho Maciel AC, Zaccaro Scelza MF. Efficacy of automated versus hand instrumentation during root canal retreatment: an ex vivo study. Int Endod J 2006;39:779-84

23. A. Kfir, I. Tsesis, E. Yakirevich, S. Matalon \& I. Abramovitz. The efficacy of five tech-niques for removing root filling material: microscopic versus radiographic evaluation. Int Endod J 2012;45:35-41 